\title{
A survey of complementary and alternative medicines use in out-patient paediatric specialities and pediatric emergency department
}

\author{
Ahuja A ${ }^{1 *}$, Al-Rashdi I ${ }^{2}$, Mezna Al-Nassri ${ }^{2}$, Al Fannah J ${ }^{3}$, Kyle G ${ }^{4}$, Al Farsi $\mathrm{S}^{5}$ and Al Hinai $\mathrm{K}^{6}$ \\ ${ }^{1}$ Professor, Oman Medical College, Oman \\ ${ }^{2}$ B.Pharm. student, Oman Medical College \\ ${ }^{3}$ Consultant Pharmacist, Royal Hospital, Muscat \\ ${ }^{4}$ Pharmacy College, Queensland University of Technology, Austalia \\ ${ }^{5}$ Senior Consultant Paediatrician, Royal Hospital, Muscat \\ ${ }^{6}$ Senior Consultant Haematology/Oncology, Royal Hospital, Muscat
}

\begin{abstract}
Complementary and alternative medicine (CAM) is defined as a general term which can be used to represent a group of diverse medical modalities, practices, and products. This study was intended to measure the prevalence of CAM use in out-patient pediatric specialties and pediatric emergency medicine department at a tertiary hospital in Oman and explore types of CAM use. All patients attending the out-patient and emergency departments at Royal hospital were asked to participate in the study. 158 patients/guardians were interviewed. $36.6 \%$ of the patients used olive oil as CAM. Hence it was considered as the most common of all $\mathrm{CAM}$ used. The results showed that $63.3 \%$ of the patients used CAM for treatment/ symptom relief as a reason for CAM use.
\end{abstract}

\section{Introduction}

Complementary and alternative medicine is defined as the 'diagnosis, treatment and or prevention which complements mainstream medicine by contributing to a common whole, by satisfying a demand not met by orthodoxy or by diversifying the conceptual framework of medicine. It is also identified as a general term which can be used to represent a group of diverse medical modalities, practices, and products [1]. WHO defines CAM as a broad set of healthcare practices that are not integrated into the dominant healthcare system. The use of complementary and alternative medicine (CAM) is widely documented in the literature. The concern is that CAM may interfere with mainstream medicine and it is difficult to know to what extent. Without knowing the extent, CAM use is prevalent in children, especially the vulnerable children. Little is known about the difference between healthy and chronically ill children with a focus on prevalence, reasons for use/non-use, costs, adverse effects (AE) and sociodemographic factors [2].

CAM popularity has risen in the last decade. Information about its use by Pediatric patients in palliative care is still scarce [3]. The systematic review is available from 2000-2001 to estimate CAM prevalence in US. Through surveys on CAM in general, the average one-year prevalence of use of CAM was $41.1 \%$ and the average lifetime prevalence was $51.8 \%$. Herbal medicine was the most popular CAM, followed by homeopathy, aromatherapy, massage and reflexology [4]. In addition, National estimates of the use of complementary health approaches among children aged 4-17 years in the United States is presented via this report. Selected modalities are compared for 2007 and 2012 to examine changes over time [5].
United States is using Complementary and alternative medicine (CAM) widely. It is used in conjunction with conventional medicine. Some CAM practitioners recommend against vaccination, and children who saw naturopathic physicians or chiropractors were less likely to receive vaccines and more likely to get vaccine-preventable diseases. Nothing is known about how child CAM usage affects influenza vaccination [6].

Examining the prevalence and predictors of complementary and alternative medicine (CAM) use was the purpose of some studies. Also, parental perceptions of CAM efficacy in a large, geographically diverse sample of children with Autism Spectrum Disorders (ASD) [7] was the subject of some studies.

The usage of complementary and alternative medicines in an outpatient pediatric neurology clinic, and to assess family attitudes toward the efficacy of complementary and alternative medicines versus prescription medications was studied as part of the research by some scientists. Complementary and alternative medicine is an important element of the modern health care landscape. There is limited information about whether and to what extent, families perceive its utility in childhood neurological disorders [8].

Correspondence to: Alka Ahuja, Professor of Pharmaceutics and Head of Research, Oman Medical College, Muscat, Sultanate of Oman, E-mail: alkaahuja@yahoo.com

Received: November 20, 2017; Accepted: December 18, 2017; Published: December 22, 2017 
National estimates of the use of complementary health approaches among children aged 4-17 years in the United States was presented via a report. Selected modalities were compared for 2007 and 2012 to examine changes over time [9]

Prevalence of Medical pluralism throughout the Western world became popular in spite of efforts to legitimize Western biomedical healthcare use "conventional medicine" and thereby relegate all nonphysician-related forms of healthcare to the "other" category. These "other" practitioners have been referred to as "unconventional", "alternative" and "complementary", among other terms throughout the past half century [10].

One study indicated that CAM use was high among pediatric specialty clinic outpatients and was much greater in the western than in the central hospitals in Canada. Most respondents felt that their CAM use was helpful with few or no harms associated. The most common CAM products currently used were multivitamins/minerals, herbal products, and homeopathic remedies. The most common CAM practices currently used are massage, chiropractic, relaxation, and aromatherapy [11]. Use of complementary and alternative medicines (CAM) in children is general and is possibly increasing. The study was conducted in Germany over a four-week period in 2004 and they found that main reasons for use was to strengthen the immune system, physical stabilization and to increase healing chances/maintain health. Also, CAM use was high, and most parents would recommend certain CAM (94\%).Moreover, $79 \%$ of the users informed a physician about CAM use and side effects were rarely reported (4\%) [12].

Complementary and alternative medicine (CAM) is widely used in the European Union (EU) as suggested by studies. Herbal medicine was most commonly reported, and CAM users were mainly women. In addition, the most common reason to use CAM was dissatisfaction with conventional care to management of musculoskeletal problems [13]

The use of Complementary and alternative medicine (CAM) for pediatric asthma is increasing and previous studies linked CAM use with decreased adherence to conventional asthma medicines. However, these studies were limited by cross-sectional design. Moreover, many families incorporated different health belief systems simultaneously to control asthma. As CAM use becomes more prevalent, it is important for physicians to ask about CAM use in a nonjudgmental fashion [14].

One systematic review was done to estimate the prevalence and use of complementary and alternative medicine (CAM) in UK and was done between $1^{\text {st }}$ January 2000 to $7^{\text {th }}$ October 2011. The most popular CAM herbal medicine was followed by homeopathy, aromatherapy, massage and reflexology. In addition, healthcare professionals should responsibly advise their patients about the use of CAM [15].

Complementary and alternative medicine therapies are associated with mental health in post disaster environment and interview was done between 2010 and 2012 as a cross-sectional study. The most common CAM therapies were multivitamins, aromatherapy and massage and were protective for depression [16].

Complementary and alternative therapies are used in cases of childhood cancer. One study was done by cross-sectional design, questionnaire and face-to-face interviews. They found that the mean age of the children was 8 years and prevalence of use of CAM among parent's children with cancer was not negligible. In addition, the researchers' belief that health professionals must be informed about the use of CAM and its methods and given information about use of CAM with conventional treatment [17].
On the other hand, adverse event has been inconclusive with some CAM herbals which were used to treat disease for example, Aloe vera in the treatment of psoriasis, cranberry in cystitis prevention, echinacea for the prevention of common cold and pomegranate for the prevention/treatment of cardiovascular problems [18].

Increasing interests to complementary and alternative medicine (CAM) are seen in chronic inflammatory bowel disease (IBD) that conventional therapies do not show any symptomatic relief or control disease and may cause side effects [19].

More than $30 \%$ of patients do not respond to pharmacologic interventions for headache, so as a result such patients started to utilize CAM therapy to manage headache and avoid side effects of medication. Examples include nutritional therapies like herbal remedies and vitamin or mineral supplementation and relaxation therapy, biofeedback therapy, cognitive-behavioral therapy which were included as behavioral treatments [20-21]

The identification of Complementary and alternative medicine (CAM) as therapy that is not included under conventional medicine was used to treat multiple sclerosis (MS) patients but because of the complexity and potential severity of the disease, parents were advised to be careful to use it.

Hence, we can conclude that physicians need to understand and know about the use of CAM amongst the children.

\section{Objectives of the study}

The objectives of the present study were:

1. To identify the extent of CAM use amongst children attending outpatient clinics and emergency departments in a tertiary care hospital in Oman.

2. To identify the type of CAM that is being used.

3. To study its effect on the patients and learn how to avoid this.

\section{Experimental}

\section{Type of study}

The present study was a cross-sectional survey of children attending out-patient pediatrics clinic and pediatric emergency department at the tertiary care hospital specialty. The Questionnaire was administered to the parents and face-to-face interviews were conducted. The initial English version of the questionnaire was initially obtained from the literature which was translated to Arabic by the two researchers and section of it was back translated between the two researchers to ensure accuracy of translation. (There exists no standard survey instrument for assessing pediatric CAM, however, the questionnaire for this study was designed using different surveys used in the literature.)

\section{Hypothesis}

CAM interferes with mainstream medicine.

\section{Subjects and settings}

This study wasintended to measure the prevalence of complementary and alternative medicine (CAM) use in out-patient pediatric specialties at a tertiary care hospital and explore types of CAM use in Oman. All patients attending the out-patient and emergency departments at a tertiary care hospital (Royal hospital) were asked to participate in the study over 1 week in July 2016. 158 patients/guardians were informed about the purpose of the study and were interviewed. 


\section{Approval from the research and ethical committee, Royal Hospital}

Prior to data collection, a research application form was completed and submitted to the Research and Ethical review committee of tertiary care hospital (Royal Hospital). The proposal was approved by the tertiary care hospital Ethical review committee.

\section{Data collection and statistical analysis}

The Data collection was done at the Royal hospital.

The data was obtained through the survey (questionnaires) and was analyzed descriptively using frequency table and cross tabulation and graphically using charts. Chi-square test of independence was also used to obtain inferential conclusions about any two variables of interest. These methods and tests were conducted using statistical package for the social sciences (SPSS). The questionnaire used is shown in Appendix 1.

\section{Results}

Data collection was commenced after obtaining the approval by Royal hospital. Patients who visited the out-patient department between $17^{\text {th }}$ July 2016 and $25^{\text {th }}$ July 2016 at the out-patient and emergency department were approached and requested to complete the questionnaires. In pediatric clinic, 117 patients visited as outpatients and 41 patients visited emergency department.

Table 1 shows the number of people attending to out-patient and emergency departments. $117(74.1 \%)$ patients attended the outpatient department and 41 (25.9\%) patients attended the emergency department.

Table 2 shows the patients on basis of gender who agreed to answer questionnaires in each department.

Figure 1 illustrates that 56 patients (35.4\%) who participated in this study were from Muscat. The least percentage was from AL Wusta, ALBuraimi, Dofar and AL Yaman (0.6\%) (only 1 patient from each of these regions).

Figure 2 illustrates that $63 \%$ of people were visiting the hospital with pre-existing diseases, while $36.94 \%$ were not.

Table 3 shows that 102 patients (64.56\%) were without prescribed medication, while 56 patients ( $35.44 \%$ ) were on medication.

Figure 3 illustrates that about $34.62 \%$ of the patients/guardians informed their healthcare provider about CAM use, while $65.38 \%$ did not inform about CAM use for their pediatrics.

Table 4 shows that 100 people (63.3\%) used CAM for treatment/ relief as a reason for CAM use. 133 people $(71.5 \%)$ confirmed that the effect of CAM use was excellent. 121 people (76.6\%) were completely satisfied after CAM use and 157 people (99.4\%) did not face any adverse event after using CAM.

Figure 4 illustrates that $36.6 \%$ of patients used olive oil, which was considered as the most common of all CAMs used.

Table 1. Percentage of pediatric patients attending different departments.

\begin{tabular}{|c|c|c|c|c|c|}
\hline \multicolumn{2}{|c|}{} & Frequency & Percent & $\begin{array}{c}\text { Valid } \\
\text { Percent }\end{array}$ & $\begin{array}{c}\text { Cumulative } \\
\text { Percent }\end{array}$ \\
\hline Valid & OPD & 117 & 74.1 & 74.1 & 74.1 \\
\hline & ER & 41 & 25.9 & 25.9 & 100.0 \\
\hline & Total & 158 & 100.0 & 100.0 & \\
\hline
\end{tabular}

Table 2. Percentage of patients on basis of gender

\begin{tabular}{|c|c|c|c|c|c|}
\hline \multicolumn{2}{|c|}{} & Frequency & Percent & $\begin{array}{c}\text { Valid } \\
\text { Percent }\end{array}$ & $\begin{array}{c}\text { Cumulative } \\
\text { Percent }\end{array}$ \\
\hline Valid & Male & 100 & 63.3 & 63.3 & 63.3 \\
\hline & Female & 58 & 36.7 & 36.7 & 100.0 \\
\hline & Total & 158 & 100.0 & 100.0 & \\
\hline
\end{tabular}

Table 3. Percentage of patients on medication and without medication.

\begin{tabular}{|c|c|c|c|c|c|}
\hline \multicolumn{2}{|c|}{} & Frequency & Percent & $\begin{array}{c}\text { Valid } \\
\text { Percent }\end{array}$ & $\begin{array}{c}\text { Cumulative } \\
\text { Percent }\end{array}$ \\
\hline Valid & No & 102 & 64.6 & 64.6 & 64.6 \\
\hline & Yes & 56 & 35.4 & 35.4 & 100.0 \\
\hline & Total & 158 & 100.0 & 100.0 & \\
\hline
\end{tabular}

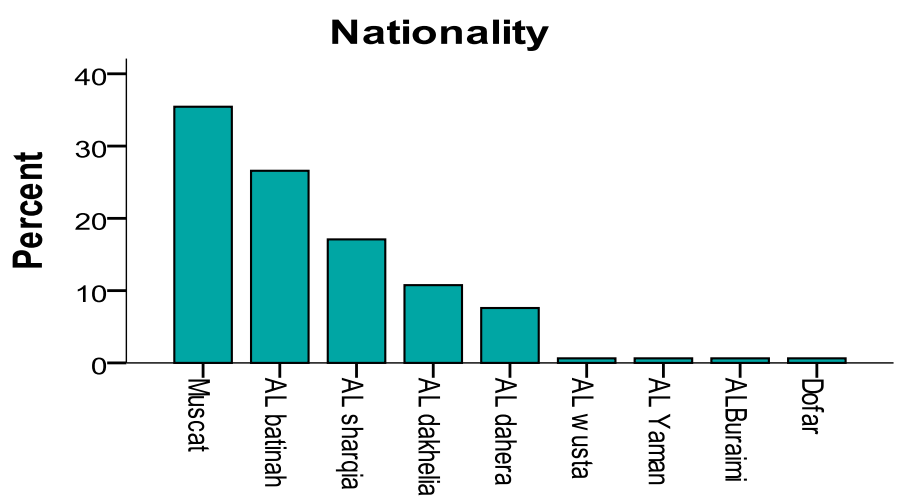

Figure 1. Plot of percent patients from various regions.

\section{Pre-existing diseases}

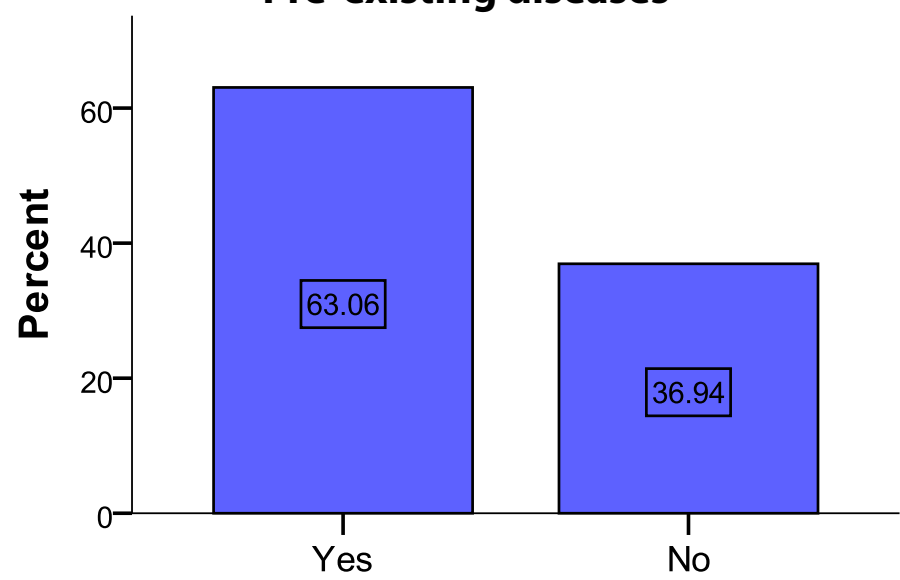

Figure 2. Percentage of patients visiting the hospital with previous diseases/illness.

Have you previously informed your healthcare provider about your CAM use?

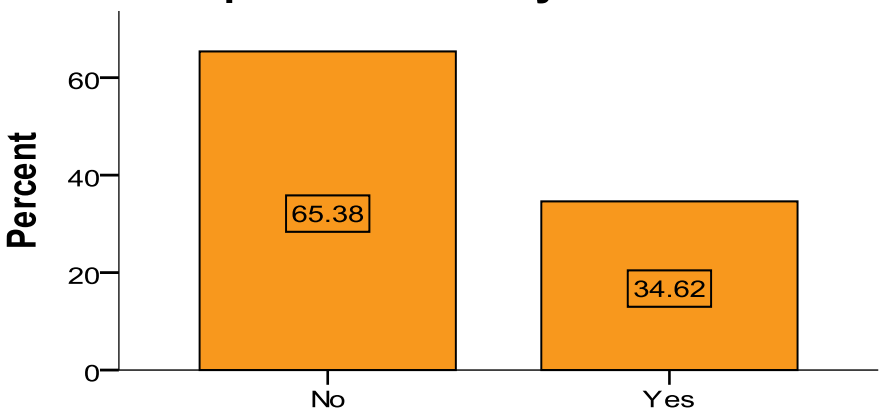

Figure 3. Percentage of patients who informed the health care provider about CAM use. 


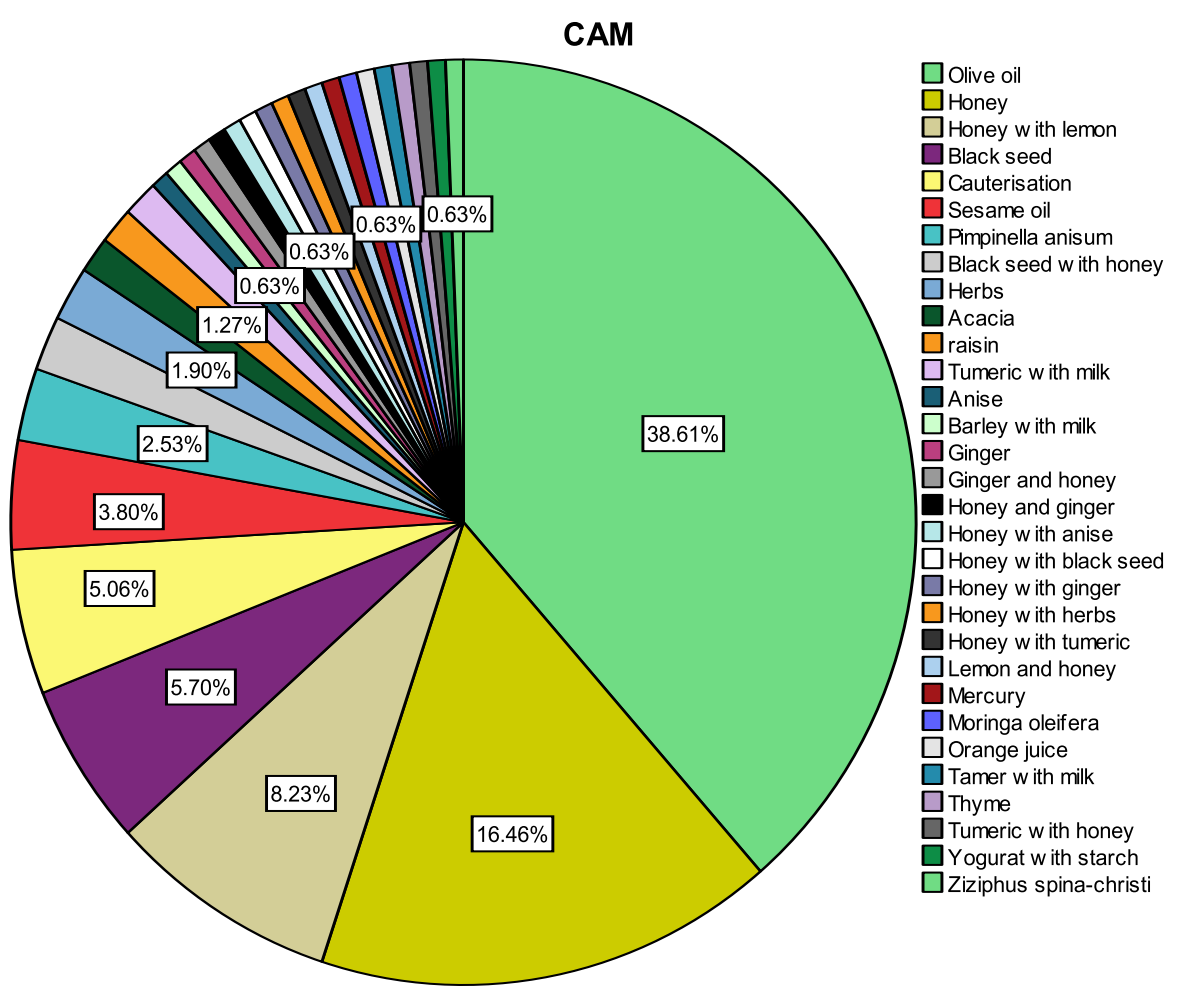

Figure 4. Illustrates that $36.6 \%$ of patients used olive oil, which was considered as the most common of all CAMs used.

Table 4. CAM use, effects, satisfaction, ADR

\begin{tabular}{|l|l|l|l|}
\hline \multirow{5}{*}{ Reasons for CAM Use } & Count & Column N \% \\
\hline & $\begin{array}{l}\text { Treatment relief of Symptom } \\
\text { Prevention of disease/ }\end{array}$ & 100 & $63.3 \%$ \\
\hline & Symptoms & 8 & $5.1 \%$ \\
\cline { 2 - 3 } & Health promotion & 39 & $24.7 \%$ \\
\hline \multirow{5}{*}{ Effect of CAM Use } & Others & 11 & $7.0 \%$ \\
\hline & Excellent & 0 & $.0 \%$ \\
\hline & Good & 113 & $71.5 \%$ \\
\hline & Fair & 22 & $13.9 \%$ \\
\hline & Poor & 16 & $10.1 \%$ \\
\hline & Very poor & 2 & $1.3 \%$ \\
\hline \multirow{5}{*}{ Satisfaction after CAM use } & Completely satisfied & 121 & $3.2 \%$ \\
\hline & Somewhat satisfied & 25 & $76.6 \%$ \\
\hline & $\begin{array}{l}\text { Neither satisfied nor } \\
\text { dissatisfied }\end{array}$ & 4 & $15.8 \%$ \\
\hline & Somewhat dissatisfied & 3 & $2.5 \%$ \\
\hline & Completely dissatisfied & 5 & $3.2 \%$ \\
\hline Adverse reaction/ Events & NO & 157 & $99.4 \%$ \\
\hline & YES & 1 & $.6 \%$ \\
\hline
\end{tabular}

\section{CAM1: USE, EFFECTS, Satisfaction, ADR}

\section{Discussion}

- $36.6 \%$ of the patients used olive oil. Hence it was considered as the most common of all CAM used.

- $63.3 \%$ of the patients used CAM for treatment/ symptom relief as a reason for CAM use.

- $71.5 \%$ of the patients felt that the effect of CAM use was excellent.

- $76.6 \%$ of the patients were completely satisfied after CAM use.
- $99.4 \%$ of the patients did not face any adverse reaction/ events after using CAM.

- $74 \%$ of the patients attended OPD department, while $25.95 \%$ of the patients attended ER department.

- $64.56 \%$ of the patients were without previous prescribed medication, while $35.44 \%$ of the patients were on medication.

- $63.29 \%$ of the patients were males and $36.71 \%$ were females.

- About $35 \%$ of the patients were from Muscat.

- $63 \%$ of the patients were visiting the hospital with pre-existing diseases, while $36.94 \%$ were not visiting with pre-existing diseases.

- $34.62 \%$ of the patients were being informed about CAM use, while $65.38 \%$ were not.

\section{Conclusion}

We can conclude that highest amount of CAM use was of Olive oil and majority of pediatric patients did not experience any adverse effect. Further research on a broader scale is needed and maybe at different times of year as there might be seasonal use of CAM.

\section{References}

1. Yael Keshet (2016) Complementary and Alternative Medicine, Wiley Blackwell online library

2. Ventola CL (2010) Current Issues Regarding Complementary and Alternative Medicine $(\mathrm{CAM})$ in the United States: Part 2: Regulatory and Safety Concerns and Proposed Governmental Policy Changes with Respect to Dietary Supplements. P T 35: 514-522. [Crossref]

3. Medicine (CAM) in the United States Part 1: The Widespread Use of CAM and the Need for Better-Informed Health Care Professionals to Provide Patient 
4. Ventola CL (2010) Current Issues Regarding Complementary and Alternative Medicine (CAM) in the United States: Part 1: The Widespread Use of CAM and the Need for Better-Informed Health Care Professionals to Provide Patient Counseling. P T 35: 461468. [Crossref]

5. Tim Schütze, Alfred Längler, Tycho Jan Zuzak, Pia Schmidt, Boris Zernikow, et al. Use of complementary and alternative medicine by pediatric oncology patients during palliative care. Supportive Care in Cancer 24: 2869-2875 [Crossref]

6. Paul Posadzki, Leala K Watson, Amani Alotaibi, Edzard Ernst (2013) Prevalence of use of complementary and alternative medicine (CAM) by patients/consumers in the UK: systematic review of surveys. Clin Med 13: 2126-2131. [Crossref]

7. Lindsey, I.Black, Tainya C.Clarke, Patricia M.Barnes, et al. (2015) Use of Complementary Health approaches among Children aged 4-17 years in the United States: National Health Interview Survey. Natl Health Stat Report 78: 1-19 [Crossref]

8. William K Bleser, Bilikisu Reni Elewonibi, Patricia Y Miranda, Rhonda BeLue (2016) Complementary and Alternative Medicine and Influenza Vaccine Uptake in US Children Pediatrics 138: pii: e20154664 [Crossref]

9. Ashli A Owen-Smith, StephenBent, Frances L.Lynch, Karen J Coleman, Vincent M.Yau, et al. (2015) Prevalence and predictors of complementary and alternative medicine use in a large insured sample of children with Autism Spectrum Disorders, Research in Autism Spectrum Disorders 17: 40-51. [Crossref]

10. Daniel Kenney, Sarah Jenkinsm, Paul Youssef, Suresh Kotagal (2016) Patient Use of Complementary and Alternative Medicines in an Outpatient Pediatric Neurology. Clinic Pediatric Neurology 58: 48-52. [Crossref]

11. Mary G Fowler, Min Qin, Susan A Fiscus, Judith S Currier, Patricia M Flynn, et al. (2016) Benefits and Risks of Antiretroviral Therapy for Perinatal HIV Prevention. $N$ Engl J Med 375: 1726-1737

12. Jeremy Y Ng, Heather S Boon, Alison K Thompson, Cynthia R Whitehead (2016) making sense of "alternative", "complementary", "unconventional" and "integrative" medicine: exploring the terms and meanings through a textual analysis, BMC Complementary and Alternative Medicine BMC series - open, inclusive and trusted 16: 134

13. Denise Adams, Simon Dagenais, Tammy Clifford, Lola Baydala, W James King (2013) Complementary and Alternative Medicine Use by Pediatric Specialty Outpatients PEDIATRICS 131: 225-232
14. Sven Gottschling, BenjaminGronwald, SarahSchmitt, ChristineSchmitt, AlfredLängle, et al. (2013) Use of complementary and alternative medicine in healthy children and children with chronic medical conditions in Germany. Complementary Therapies in Medicine 21: S61-S69 [Crossref]

15. E ardley S, Bishop FL, Prescott P, Cardini F, Brinkhaus B, et al. (2012) A systematic literature review of Complementary and Alternative Medicine Prevalence in EU. Forsch Komplementmed 19: 18-28 [Crossref]

16. Julie C Philp, Judy Maselli, Lee M Pachter, Michael D Cabana (2012) Complementary and Alternative Medicine Use and Adherence with Pediatric Asthma Treatment PEDIATRICS 129: 1-7

17. Paul Posadzki, Leala K Watson, Amani Alotaibi, Edzard Ernst (2013) Prevalence of use of complementary and alternative medicine (CAM) by patients/consumers in the UK: systematic review of surveys, Clinical medicine, 13: 126-31. [Crossref]

18. Veronica Barcelona de Mendoza, Emily Harville, Jane Savage, Gloria Giarratano (2016) Association of Complementary and Alternative Therapies With Mental Health Outcomes in Pregnant Women Living in a Postdisaster Recovery Environment Journal of Holistic Nursing 34: 259-270 [Crossref]

19. Meltem Kurtuncu, Hicran Yildiz, Latife Utas Akhan (2016) The use of complementary and alternative therapies in childhood cancer: a questionnaire based on a descriptive survey from the western black sea region of turkey, Afr. J. Tradit. Complement Altern Med 13: 3

20. Angelo A Izzo, Sung Hoon-Kim, Rajan Radhakrishnan, Elizabeth M Williamson (2016) A Critical Approach to Evaluating Clinical Efficacy, Adverse Events and Drug Interactions of Herbal Remedies. phytotherapy research 30: 691-700. [Crossref]

21. Lena Oxelmark, Annelie Lindberg, Robert Löfberg, Berit Sternby, Anders Eriksson (2016) Use of complementary and alternative medicine in Swedish patients with inflammatory bowel disease: a controlled study. Eur J Gastroenterol Hepatol 28 : 1320-1328. [Crossref]

22. Holroyd Kenneth, Mauskop alexander (2003) Complementary and alternative treatments. Neurology 60: S58-S62.

23. Allen C. Bowling (2013) Complementary and alternative treatments. Future medicine

Copyright: (C2017 Ahuja A. This is an open-access article distributed under the terms of the Creative Commons Attribution License, which permits unrestricted use, distribution, and reproduction in any medium, provided the original author and source are credited. 